\title{
Serious Adverse Effects of Gamma Knife Radiosurgery for Mesial Temporal Lobe Epilepsy
}

\author{
Tetsuro KAWAmurA, ${ }^{1}$ Hiroaki ONISHI, ${ }^{1}$ Yukihiko KOHDA, ${ }^{1}$ and Genjiro HiROSE ${ }^{2}$
}

\author{
Departments of ${ }^{1}$ Neurosurgery and ${ }^{2}$ Neurology, \\ Asanogawa General Hospital, Kanazawa, Ishikawa
}

\begin{abstract}
Gamma knife radiosurgery (GKRS) for mesial temporal lobe epilepsy (MTLE) has been proposed as an alternative to surgical resection. We report serious adverse effects of the treatment after follow-up periods over 9 years in 11 patients treated with GKRS between 1997 and 2000 . The target volume of the entorhinoamygdalohippocampectomy area was 4.8-17.1 ml. Marginal dose of 20-25 Gy to the 50\% isodose was delivered. One patient was drowned after suffering seizure 7 months after GKRS. Two patients did not show any reduction in seizure frequency over 9 and 18 months. Both patients requested open surgery and became seizure-free postoperatively. Four of the other eight patients were classified as Engel's class I within 4 years after GKRS. One of the four patients experienced symptomatic radiation-induced cerebral edema transiently, one developed radiation necrosis and required surgery 5 years after GKRS, and one developed cognitive impairment with hemiparesis 10 years after GKRS. Magnetic resonance (MR) imaging showed a large cyst in the irradiated temporal lobe. This patient recovered fully after the cyst excision. Only one patient became seizure-free and antiepileptic drug-free without symptomatic radiation-induced complications. However, MR imaging revealed abnormal enhancement, cyst formation, and diffuse white matter change in the irradiated temporal lobe 9 years after GKRS. GKRS for MTLE causes adverse effects of delayed seizure remission and symptomatic radiationinduced complications. Therefore, GKRS cannot be considered as an ideal alternative to surgery for MTLE. Long-term follow-up studies including MR imaging with contrast medium are required for the patients even after successful control of seizures.
\end{abstract}

Key words: mesial temporal lobe epilepsy, radiosurgery, gamma knife, radiation necrosis, cyst formation

\section{Introduction}

Mesial temporal lobe epilepsy (MTLE) is the most common surgically remediable syndrome. A randomized controlled trial demonstrated that surgery for intractable MTLE was superior to prolonged medical treatment. ${ }^{37)}$ Furthermore, long-term followup studies of more than 5 years reported that the seizure-free rate after temporal lobe surgery was approximately $50-70 \% .^{7,12,17,34)}$ Both anterior temporal lobectomy and selective amygdalohippocampectomy for MTLE lead to almost same seizure outcomes. ${ }^{27,33)}$ Resective surgery for MTLE has shown favorable outcome and safety, but is not free from failure of seizure control, morbidity, and relapse of seizure. ${ }^{1,23,26,28,32)}$ Given such faults of conventional surgery, other treatment options should be developed with better outcome and lower morbidity than

Received October 17, 2011; Accepted November 7, 2011 open surgery.

One of the alternatives to open surgery is gamma knife radiosurgery (GKRS). GKRS for MTLE using $24 \mathrm{~Gy}$ resulted in seizure-free rate of $60 \%$ after 6-10 years follow-up. ${ }^{3,24}$ Another pilot study reported that $67 \%$ of patients with MTLE were seizure-free after GKRS using 20 or $24 \mathrm{~Gy}$ at the 36-month followup evaluation. ${ }^{2)}$ However, some studies reported that none of the patients became seizure-free after GKRS. ${ }^{13,30,36)}$ To date, the seizure outcome in patients with MTLE after GKRS has not been consistent. $^{22)}$ In the studies with good seizure outcome, non-invasiveness and safety were emphasized as major advantages of GKRS over resective surgery. However, some disadvantages of this treatment, such as delayed response and delayed radiation necrosis (DRN) were identified. Long-term effectiveness and safety of this treatment have not been established yet.

We report the long-term seizure outcome and adverse effects of GKRS for MTLE in 11 patients after 
follow-up periods of over 9 years.

\section{Materials and Methods}

Eleven patients, 10 women and one man aged 41-66 years, were selected for GKRS from October 1997 to September 2000. All patients had medically intractable complex partial seizures with or without secondary generalization. Medically intractable MTLE in our clinic is defined as complex partial seizure once a week or more than four seizures a month with or without generalization. Presurgical studies included outpatient electroencephalography (EEG), video EEG, axial and coronal $\mathrm{T}_{1}$ - and $\mathrm{T}_{2}$-weighted, proton-density, and fluid-attenuated inversion recovery magnetic resonance (MR) imaging of the brain, single-photon emission computed tomography (SPECT), and positron emission tomography (PET), as well as routine neurological and psychological assessments. Nine patients had rhythmic activities in the unilateral anterior temporal derivation on ictal EEGs. Two of the 11 patients needed EEGs with subdural electrodes to confirm unilateral MTLE. MR imaging showed abnormal findings in the unilateral medial temporal structure with hippocampal atrophy and/or sclerotic changes in all 11 patients. Interictal technetium-99m ethyl cysteinate dimer SPECT or fluorine-18-fluorodeoxyglucose PET studies confirmed the lesion side on MR imaging with low uptake in the unilateral temporal lobe in all patients. All findings in these evaluations were consistent with the clinical diagnosis of unilateral MTLE. This study was approved by the hospital review board. All patients gave written informed consent after receiving explanations of the diagnosis of intractable MTLE, and the rationales and the usual procedures for determining suitability for GKRS.

Eight patients had the left MTLE and three had right MTLE. The target volume varied from 4.8 to $17.1 \mathrm{ml}$ (mean $10.6 \mathrm{ml}$ ), which included the anterior $2.5 \mathrm{~cm}$ of the hippocampus, the amygdala, and the parahippocampal gyrus. The marginal prescription dose to the $50 \%$ isodose line also varied slightly from 20 to $25 \mathrm{~Gy}$ (mean $23 \mathrm{~Gy}$ ). The adjacent visual pathway and the brain stem received less than 8 and 15 Gy, respectively. The $10-G y$ volume was 16.5 to 76.5 $\mathrm{ml}$ (mean $36.9 \mathrm{ml}$ ). All treatment plans were calculated by Leksell GammaPlan software (Elekta AB, Stockholm, Sweden). GKRS was performed with the model B Leksell Gamma Knife (Elekta AB).

\section{Results}

Clinical characteristics and results are summarized in Table 1. Three of the 11 patients dropped out of the study and could not be evaluated for surgical outcome. One patient (Case 9) was drowned after suffering seizure at 7 months after GKRS. Two others (Cases 1 and 5) requested open surgery because of incomplete seizure outcome over 9 and 18 months after the treatment.

The seizure outcomes of eight patients who underwent GKRS were assessed by Engel's classification at 4 years. Three patients (Cases 4,6 , and 11) were classified as class IA with delay of complete control by 1 year in one, 2 years in one, and 4 years in one patient. The three patients also became antiepileptic drug (AED)-free. Case 3 was classified as class IB, two patients as IIIA, and two patients as IVB. Two patients with class IA and IB outcomes needed management by open surgery for complications of GKRS at 118 and 60 months, respectively (Table 1).

Table 1 Clinical characteristics and results

\begin{tabular}{|c|c|c|c|c|c|c|c|c|c|}
\hline $\begin{array}{l}\text { Case } \\
\text { No. }\end{array}$ & Sex & $\begin{array}{l}\text { Age at } \\
\text { GKRS } \\
\text { (yrs) }\end{array}$ & $\begin{array}{l}\text { MTLE } \\
\text { side }\end{array}$ & $\begin{array}{l}\text { Prescription } \\
\text { dose (Gy) }\end{array}$ & $\begin{array}{l}\text { Target } \\
\text { volume } \\
(\mathrm{ml})\end{array}$ & $\begin{array}{l}\text { 10-Gy } \\
\text { volume } \\
\text { (ml) }\end{array}$ & $\begin{array}{c}\text { Seizure outcome* } \\
\text { of GKRS at } \\
4 \text { years }\end{array}$ & $\begin{array}{c}\text { Delay of } \\
\text { seizure } \\
\text { cessation (mos) }\end{array}$ & $\begin{array}{l}\text { Interval between } \\
\text { GKRS and open } \\
\text { surgery (mos) }\end{array}$ \\
\hline 1 & $\mathrm{~F}$ & 46 & lt & 20 & 12.5 & NA & dropout & - & 9 \\
\hline 2 & $\mathrm{~F}$ & 50 & lt & 20 & 12.2 & 32.0 & IIIA & - & - \\
\hline 3 & $\mathrm{~F}$ & 43 & lt & 20 & 17.1 & 46.8 & IB & 24 & 60 \\
\hline 4 & $\mathrm{~F}$ & 55 & lt & 23 & 9.0 & 27.6 & IA & 12 & - \\
\hline 5 & $\mathrm{~F}$ & 41 & lt & 23 & 9.6 & 30.8 & dropout & - & 18 \\
\hline 6 & $\mathrm{~F}$ & 66 & $\mathrm{rt}$ & 23 & 9.5 & 29.7 & IA & 48 & 118 \\
\hline 7 & $\mathrm{~F}$ & 55 & lt & 24 & 9.3 & 31.1 & IVB & - & - \\
\hline 8 & $\mathrm{~F}$ & 65 & lt & 25 & 11.3 & 46.1 & IVB & - & - \\
\hline 9 & $\mathrm{~F}$ & 51 & $\mathrm{rt}$ & 25 & 7.2 & 32.3 & dropout & - & - \\
\hline 10 & M & 43 & $\mathrm{rt}$ & 25 & 14.2 & 76.5 & IIIA & - & - \\
\hline 11 & $\mathrm{~F}$ & 52 & lt & 25 & 4.8 & 16.5 & IA & 24 & - \\
\hline
\end{tabular}

*Engel's classification. F: female, GKRS: gamma knife radiosurgery, M: male, MTLE: mesial temporal lobe epilepsy, NA: not available. 

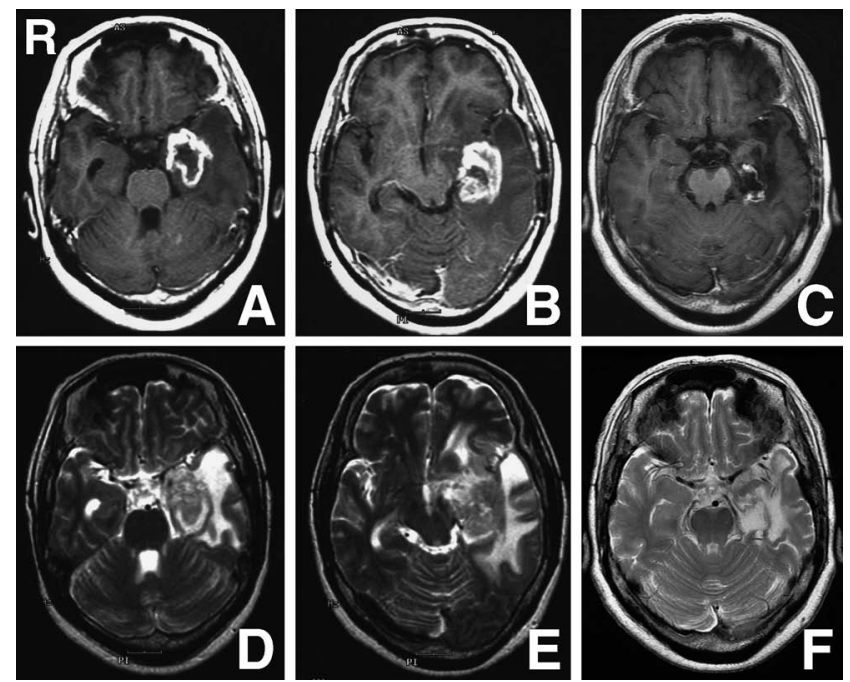

Fig. 1 Case 4. $T_{1}$-weighted (A-C) and $T_{2}$-weighted (D-F) magnetic resonance images at 12 months after gamma knife radiosurgery (GKRS) showing a thick irregular rim-enhanced mass with vasogenic edema $(A, B$, $D, E)$, and at 115 months after GKRS showing a thin rimenhanced area with a cyst in the medial temporal lobe, and increased $T_{2}$-weighted intensity beyond the target volume $(C, F)$.

Case 4, classified as IA, developed cognitive impairment, aphasia, and right hemiparesis 12 months after GKRS. MR imaging with contrast medium revealed an irregular ring-shaped enhancement in the left medial temporal lobe (Fig. 1A, B). $\mathrm{T}_{2}$-weighted MR imaging showed extensive vasogenic edema over the irradiated area (Fig. 1D, E). She required intravenous corticosteroid and glycerin for the reduction of vasogenic edema over several weeks. She recovered fully without neurological deficits after these managements. MR imaging obtained 10 years after GKRS showed a rim-enhancement area with a small cyst and increased $\mathrm{T}_{2}$-weighted intensity (Fig. 1C, F).

Delayed adverse effects occurred in Case 3 who developed severe headache, visual change with quadrant hemianopsia, and frequent partial seizures 5 years after GKRS. MR imaging and isotope studies revealed radiation necrosis with multiple small hematomas in the left temporal lobe (Fig. 2). She underwent left anterior temporal lobectomy and soon became seizure-free without neurological deficits.

Ten years after GKRS, Case 6 showed cognitive impairment and left hemiparesis. MR imaging revealed a large cyst in the right temporal lobe. MR imaging with contrast medium showed a nodular enhancement in the medial wall of the cyst (Fig. 3). She recovered completely after excision of the cyst. The biochemical components of the cyst fluid obtained
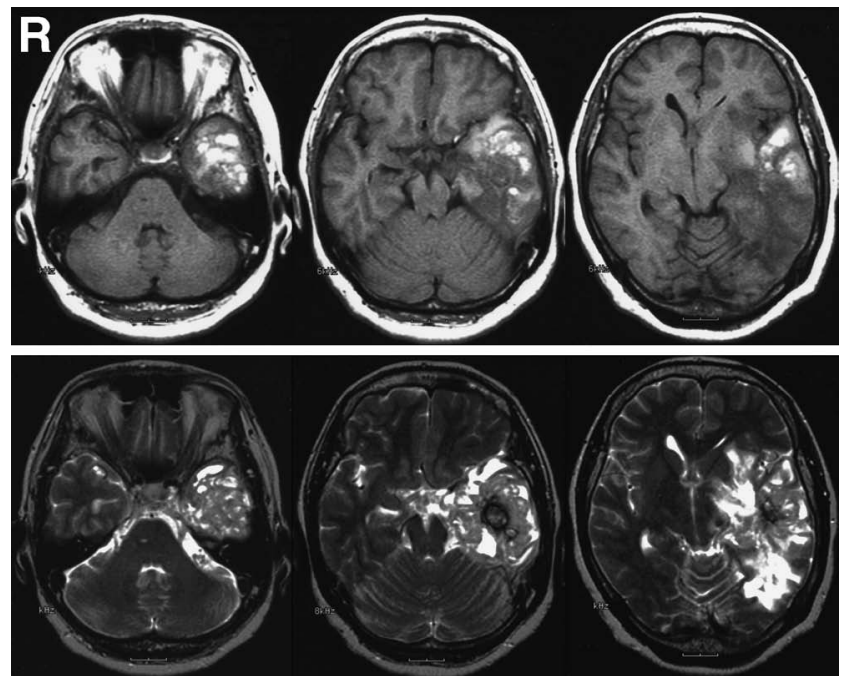

Fig. 2 Case 3. $T_{1}$-weighted (upper row) and $T_{2}$-weighted (lower row) magnetic resonance images obtained 5 years after gamma knife radiosurgery showing multiple small hematomas with extensive vasogenic edema over the treated temporal lobe.
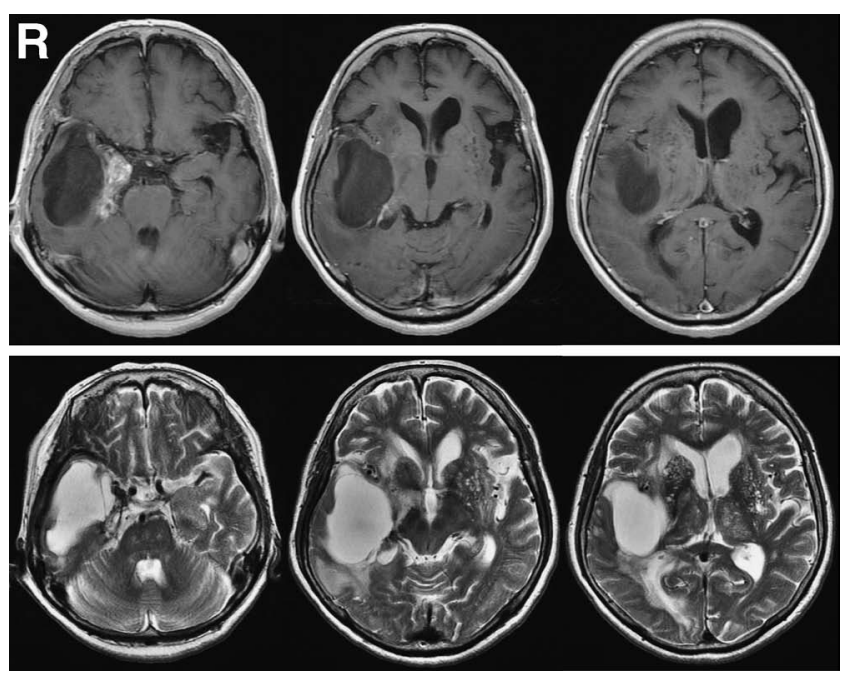

Fig. 3 Case 6. T $T_{1}$-weighted (upper row) and $T_{2}$-weighted (lower row) magnetic resonance images obtained 10 years after gamma knife radiosurgery showing nodular enhancement with a large cyst in the right temporal lobe. The $T_{2}$-weighted images reveal increased intensity around the large cyst.

at surgery were similar to those of serum. The medial cyst wall enhanced on MR imaging contained coagulation necrosis, hemosiderin deposition, and vascular changes, including hyalinization and neovascularization (Fig. 4A, B). The dilated capillaries were surrounded by many dense foamy cells (Fig. 4C). The foamy cells were identified as macrophages 


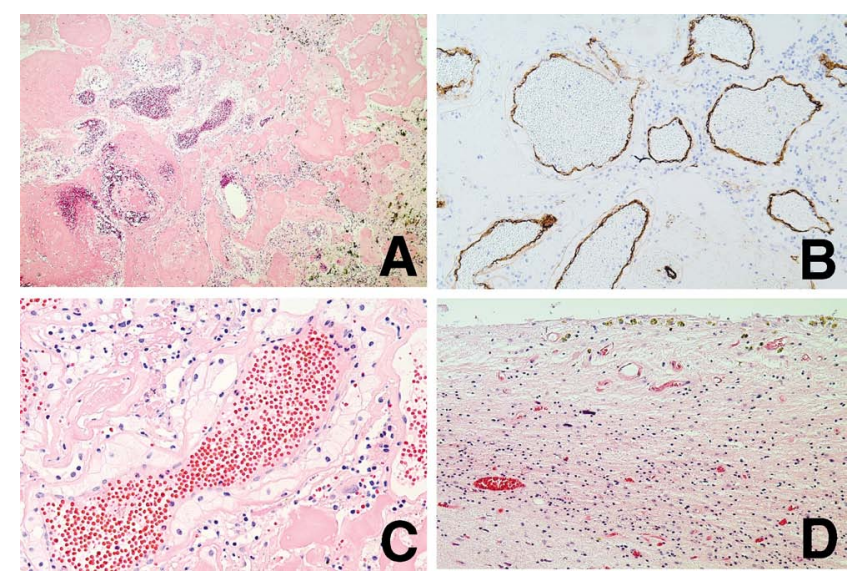

Fig. 4 Case 6. A-C: Photomicrographs of the medial wall of the cyst with contrast enhancement. Coagulation necrosis, hemosiderin deposit, and vascular changes including hyalinization and telangiectasis are noted (A: hematoxylin and eosin stain, original magnification $\times$ 40). Abnormal vessels are formed by monolayer endothelial cells (B: immunostaining for anti-CD34, original magnification $\times 100$ ). Dilated capillaries are surrounded by many dense foamy cells, and hemosiderin is not seen in the foamy macrophages (C: hematoxylin and eosin stain, original magnification $\times 100$ ). D: Photomicrograph of the lateral wall of the cyst without contrast enhancement. Hemosiderin-laden macrophages and reactive astrocytes are seen. Hematoxylin and eosin stain, original magnification $\times 100$.
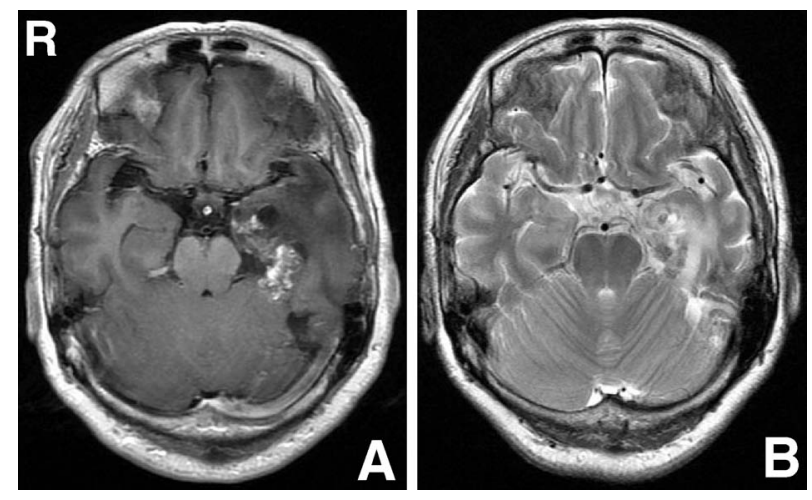

Fig. 5 Case 11. $T_{1}$-weighted (A) and $T_{2}$-weighted (B) magnetic resonance images obtained 9 years after gamma knife radiosurgery (GKRS) showing abnormal enhancement in the target area for GKRS. Small cysts with irregularly enhanced walls are also noted (A). Increased $\mathrm{T}_{2}$-weighted intensity over the target area shows no mass effect in the temporal lobe (B).

by immunohistochemical staining for CD68. The lateral wall of the cyst showing no enhancement on MR imaging contained hemosiderin-laden macrophages and reactive astrocytes (Fig. 4D). No dilated capillaries or foamy macrophages were found in the lateral wall of the cyst.

Only Case 11 became seizure-free and AED-free without symptomatic radiation-induced cerebral edema or necrosis. However, MR imaging 9 years after GKRS showed nodular enhancement with surrounding increased $\mathrm{T}_{2}$-weighted intensity and formation of small cysts in the left temporal lobe (Fig. $5)$.

\section{Discussion}

This study demonstrated that GKRS can result in seizure-free and AED-free patients with MTLE. On the other hand, this study indicated that GKRS for patients with MTLE has potentially serious adverse effects, including delayed seizure control, radiationinduced cerebral edema, DRN, and cyst formation.

Regardless of radiation-induced complications, the seizure remission rate was about $36 \%$ in this study. Seizure outcomes of GKRS for MTLE vary in published studies (Table 2). The reasons for the discrepancies among the results remain unclear. Four factors, prescribed dose, target volume, extension of the epileptogenic zone, and the follow-up period, may be related to these discrepancies. The treatment failure of GKRS may be due to either low prescribed dose or small target volume. However, GKRS with higher dose was not always more successful than that with lower dose (Table 2). Furthermore, this study showed that the target volume was not related to seizure outcome (Table 1). Extension of the epileptogenic zone may be a more important factor for the prognosis. Since the volume for effective treatment must be limited to prevent radiation-induced complications, extension of the epileptogenic zone beyond the target volume may lead to treatment failure. ${ }^{3)}$

Whether GKRS for MTLE can lead to AED-free outcome or not is important, because prolonged medication will do harm to the quality of life and effectiveness in medical economics. ${ }^{36)}$ In our study, three patients were AED-free at 4 years after the treatment. In contrast, seizures recurred during AED tapering in all patients of another series who became seizure-free after GKRS, but restoring previous medications led to remission. ${ }^{3)}$

Delay in seizure control after GKRS for MTLE has been well documented. ${ }^{2-4,11,24)}$ Significant reduction in seizures usually occurred at least 1 year after GKRS. Delayed treatment response makes evaluation of the treatment effectiveness difficult, because some patients might undergo open surgery before seizure control by GKRS. The delay may not be tolerated by the patients who are anxious to be free 
Table 2 Review of outcomes of gamma knife radiosurgery for mesial temporal lobe epilepsy

\begin{tabular}{|c|c|c|c|c|c|}
\hline Author (Year) & $\begin{array}{l}\text { No. of } \\
\text { patients }\end{array}$ & $\begin{array}{l}\text { Prescription dose } \\
\text { (Gy) }\end{array}$ & $\begin{array}{l}\text { Target volume } \\
(\mathrm{ml})\end{array}$ & $\begin{array}{l}\text { Follow-up period } \\
\text { (mos) }\end{array}$ & $\begin{array}{c}\text { Free from disabling seizures, } \\
\text { Engel's class I (\%) }\end{array}$ \\
\hline Kawai et al. (2001) ${ }^{13)}$ & 2 & 18 & $6.2,8.7$ & 30,16 & 0 \\
\hline Srikijvilaikul et al. (2004) ${ }^{30)}$ & $5^{*}$ & 20 & $6.1-8.7$ & $1-22$ & 0 \\
\hline Hoggard et al. (2008) $)^{11)}$ & 8 & 25 & $4.9-7.1$ & $24-53$ & $4(50)$ \\
\hline Bartolomei et al. (2008) ${ }^{3)}$ & 15 & 24 & $5.5-9.0$ & $>60$ & $9(60)$ \\
\hline \multirow[t]{3}{*}{ Rheims et al. $(2008)^{25)}$} & 3 & 18 & ND & $>60$ & $2(67)$ \\
\hline & 3 & 20 & & $32-82$ & $2(67)$ \\
\hline & 4 & 24 & & $37-112$ & $2(50)$ \\
\hline \multirow[t]{2}{*}{ Barbaro et al. $(2009)^{2)}$} & 17 & 20 & $5.5-7.5$ & 36 & $10(59)$ \\
\hline & 13 & 24 & & 36 & $10(77)$ \\
\hline \multirow[t]{3}{*}{ Vojtěch et al. $(2009)^{36)}$} & 6 & 18 & $5.2-6.1$ & $>60$ & $1(17)$ \\
\hline & 2 & 20 & $7.3,8.9$ & 53,138 & 0 \\
\hline & 6 & 25 & $6.6-7.6$ & $40-131$ & 0 \\
\hline
\end{tabular}

${ }^{*}$ Two of five patients in this study died 1 month and 13 months after treatment. ND: not described

from disabling seizures. In this study, two patients could not tolerate inadequate control of seizures and requested open surgery at 9 and 18 months after GKRS, respectively. In other studies, resective surgery was also performed following GKRS because of insufficient treatment effect, and most patients became seizure-free immediately after open surgery. ${ }^{3,13,25,30,36)}$ Furthermore, delayed seizure control of GKRS exposes patients to many risks such as injury, drowning, or unexpected death associated with seizure. ${ }^{22)}$ Immediate cessation of seizure seems to decrease mortality after epilepsy surgery. Evaluation of 215 patients with temporal lobe epilepsy found 3 of 148 (2\%) seizure-free patients died after surgery, compared with 8 of 67 (11.9\%) non-seizure-free patients. ${ }^{26)}$ In a series of 583 patients who underwent epilepsy surgery, only one of $258(0.4 \%)$ patients with no recurrent seizure died, whereas 18 of 325 (5.5\%) patients with recurrent seizure died. ${ }^{29)}$ These findings suggest that mortality after epilepsy surgery is associated with seizure persistence and successful surgery reduces the mortality rate among patients with MTLE. In contrast, no beneficial effects of epilepsy surgery on survival were found compared with a control group of medically treated patients with intractable epilepsy. ${ }^{31)}$ Although sudden unexpected death in epilepsy (SUDEP) has been reported in previous studies of GKRS for MTLE, ${ }^{3,30)}$ the effect of epilepsy surgery on the risk of SUDEP remains unclear. ${ }^{10,19,35)}$

One of the serious complications associated with GKRS is DRN. DRN occurs several months or years after the treatment, and sometimes open surgery is required. Case 3 developed symptomatic radiation necrosis and required anterior temporal lobectomy 5 years after treatment. Surgical treatment for medically unmanageable intracranial hypertension caused by DRN was also reported. ${ }^{2,8)}$ Significant risk factors for DRN are treatment volume and radiation dose. Increase in dose and/or target volume enhances the risk of acute radiation effect and DRN. ${ }^{18)}$ Some parameters have been evaluated to predict the risk of DRN. The median value of $10-\mathrm{Gy}$ volume, which indicates the total tissue volume receiving a dose of at least $10 \mathrm{~Gy}$, was significantly larger in patients with DRN group than in those without DRN. ${ }^{5)}$ The 10-Gy volume was considered to be the most reliable single parameter for assessing the risk of DRN, because it is associated with prescribed dose, volume, and treatment plan conformity. However, the 10-Gy volume for developing DRN is quite low in some patients. Therefore, the value of 10-Gy volume for preventing DRN completely remains to be determined.

The 1\% isonecrosis risk line indicates that the risk of radiation necrosis is less than $1 \%$ for patients treated with dose-volume points below the line. ${ }^{15)}$ This $1 \%$ line has been reevaluated and is considered to indicate a $3 \%$ to $8 \%$ risk of radiation necrosis. ${ }^{5,16}$ The $3 \%$ line is another indicator of the risk of DRN.9) This line lies below the original $1 \%$ risk line, if the target volume is larger than $0.5 \mathrm{ml}$. The dose-target diameter data of the present study were above the $1 \%$ line (data not shown), indicating that the risk rates of radiation necrosis in our cases were over $3-8 \%$. If the risk rate of radiation necrosis is required to be below $3-8 \%$, the target volume is less than $5.2 \mathrm{ml}$ for $20 \mathrm{~Gy}$ and less than $2.7 \mathrm{ml}$ for $24 \mathrm{~Gy}$ to the $50 \%$ isodose line. Such a volume may be too small to include the medial temporal structure for efficient treatment. Even in previous reports which demonstrated good seizure outcome and low morbidity, the target volume-dose at $50 \%$ isodose data was above the $1 \%$ risk line. In addition to the dose and the volume, irradiated tissue type is also a crucial factor of DRN. The normal brain parenchyma 
develops DRN more easily than tumors if the identical dose of radiosurgery is delivered.5)

Our Case 6 developed a symptomatic cyst 10 years after treatment. Cyst formation is a well known complication after GKRS for arteriovenous malformation. The incidence of cyst formation varies between $2 \%$ and $30 \% .^{14,20,38)}$ Delayed cyst formation following GKRS in 1203 consecutive patients with arteriovenous malformations was related to the duration of the follow-up period. ${ }^{20}$ The incidence of cyst formation was $3.6 \%$ in cases with follow-up period over 5 years. ${ }^{20)}$ The pathogenesis of cyst formation remains unclear. Blood vessels within area of radiation necrosis may have increased permeability so the leak of serum components possibly contributes to cyst formation. ${ }^{6}$ In our Case 6, histological examination of the medial cyst wall revealed angiogenesis, and the biochemical components of the cyst fluid were similar to those of the serum. These findings suggest that delayed cyst formation is related to radiation-induced angiogenesis and abnormal exudation from the vessels. In order to treat symptomatic cyst formation, simple aspiration of the cyst is not effective. Either placement of cyst-peritoneal shunt or resection of the cyst is required. ${ }^{21)}$

In our series, only Case 11 has remained seizurefree and AED-free without symptomatic radiationinduced cerebral edema and DRN. However, MR imaging revealed an enhanced area with small cyst formation and increased $\mathrm{T}_{2}$-weighted intensity beyond the target volume 9 years after GKRS. The target volume and prescription dose were $4.8 \mathrm{ml}$ and 25 Gy, respectively, in this case. These treatment parameters were not much different from those in previous studies. As shown in the medial cyst wall of Case 6, abnormal enhancement of the target area correlates with radiation-induced angioneogenesis and probably with breakdown of the blood-brain barrier. Since the increased $\mathrm{T}_{2}$-weighted intensity showed no mass effect, this abnormal signal was not associated with vasogenic edema. Delayed abnormal enhancement and increased $\mathrm{T}_{2}$-weighted intensity on MR imaging have been also reported in the case of GKRS for arteriovenous malformations. ${ }^{14)}$

In conclusion, GKRS for MTLE has various adverse effects such as delayed seizure remission and symptomatic radiation-induced complications. Radiation-induced change of the brain parenchyma persists over a long period. Therefore, GKRS cannot be considered as an ideal alternative to open surgery for patients with MTLE. Long-term follow-up studies including MR imaging with contrast medium are required for patients who underwent GKRS for MTLE even after complete seizure control.

\section{Acknowledgment}

We are very grateful to radiology technicians, Messrs. Wataru Taroda, Mitsuru Ishiguro, and Kohei Hasegawa for their technical support at Asanogawa Stereotactic Radiosurgery Center.

This study was presented in part at the $63^{\text {rd }}$ American Epilepsy Society Annual Meeting in Boston, Massachusetts, USA, December 4-8, 2009.

\section{References}

1) Aull-Watschinger S, Pataraia E, Czech T, Baumgartner C: Outcome predictors for surgical treatment of temporal lobe epilepsy with hippocampal sclerosis. Epilepsia 49: 1308-1316, 2008

2) Barbaro NM, Quigg M, Broshek DK, Ward MM, Lamborn KR, Laxer KD, Larson DA, Dillon W, Verhey L, Garcia P, Steiner L, Heck C, Kondziolka D, Beach R, Olivero W, Witt TC, Salanova V, Goodman R: A multicenter, prospective pilot study of gamma knife radiosurgery for mesial temporal lobe epilepsy: seizure response, adverse events, and verbal memory. Ann Neurol 65: 167-175, 2009

3) Bartolomei F, Hayashi M, Tamura M, Rey M, Fischer C, Chauvel P, Régis J: Long-term efficacy of gamma knife radiosurgery in mesial temporal lobe epilepsy. Neurology 70: 1658-1663, 2008

4) Chang EF, Quigg M, Oh MC, Dillon WP, Ward MM, Laxer KD, Broshek DK, Barbaro NM; Epilepsy Radiosurgery Study Group: Predictors of efficacy after stereotactic radiosurgery for medial temporal lobe epilepsy. Neurology 74: 165-172, 2010

5) Chin LS, Ma L, DiBiase S: Radiation necrosis following gamma knife surgery: a case-controlled comparison of treatment parameters and long-term clinical follow up. J Neurosurg 94: 899-904, 2001

6) Edmister WB, Lane JI, Gilbertson JR, Brown RD, Pollock BE: Tumefactive cysts: a delayed complication following radiosurgery for cerebral arterial venous malformations. AJNR Am J Neuroradiol 26: 11521157, 2005

7) Elsharkawy AE, Alabbasi AH, Pannek H, Oppel F, Schulz R, Hoppe M, Hamad AP, Nayel M, Issa A, Ebner A: Long-term outcome after temporal lobe epilepsy surgery in 434 consecutive adult patients. J Neurosurg 110: 1135-1146, 2009

8) Finet P, Rooijakkers H, Godfraind C, Raftopoulos C: Delayed compressive angiomatous degeneration in a case of mesial temporal lobe epilepsy treated by gamma knife radiosurgery: Case report. Neurosurgery 67: 218-220, 2010

9) Flickinger JC, Schell MC, Larson DA: Estimation of complications for linear accelerator radiosurgery with the integrated logistic formula. Int J Radiat Oncol Biol Phys 19: 143-148, 1990

10) Hennessy MJ, Langan $Y$, Elwes RDC, Binnie CD, Polkey CE, Nashef L: A study of mortality after temporal lobe epilepsy surgery. Neurology 53: 1276- 
1283, 1999

11) Hoggard N, Wilkinson ID, Griffiths PD, Vaughan $P$, Kemeny AA, Rowe JG: The clinical course after stereotactic radiosurgical amygdalohippocampectomy with neuroradiological correlates. Neurosurgery 62: 336-346, 2008

12) Jutila L, Immonen A, Mervaala E, Partanen J, Partanen K, Puranen M, Kälviäinen R, Alafuzoff I, Hurskainen H, Vapalahti M, Ylinen A: Long term outcome of temporal lobe epilepsy surgery: analyses of 140 consecutive patients. J Neurol Neurosurg Psychiatry 73: 486-494, 2002

13) Kawai K, Suzuki I, Kurita H, Shin M, Arai N, Kirino $\mathrm{T}$ : Failure of low-dose radiosurgery to control temporal lobe epilepsy. J Neurosurg 95: 883-887, 2001

14) Kihlström L, Guo WY, Karlsson B, Lindquist C, Lindqvist M: Magnetic resonance imaging of obliterated arteriovenous malformations up to 23 years after radiosurgery. J Neurosurg 86: 589-593, 1997

15) Kjellberg RN, Abe M: Stereotactic Bragg peak proton beam therapy, in Lunsford LD (ed): Modern Stereotactic Neurosurgery. Boston, Martinus Nijhoff, 1988, pp 463-470

16) Marks LB, Spencer DP: The influence of volume on the tolerance of the brain to radiosurgery. J Neurosurg 75: 177-180, 1991

17) McIntosh AM, Kalnins RM, Mitchell LA, Fabinyi GC, Briellmann RS, Berkovic SF: Temporal lobectomy: long-term seizure outcome, late recurrence and risks for seizure recurrence. Brain 127: 2018-2030, 2004

18) Nedzi LA, Kooy H, Alexander E 3rd, Gelman RS, Loeffler JS: Variables associated with the development of complications from radiosurgery of intracranial tumors. Int J Radiat Oncol Biol Phys 21: 591-599, 1991

19) Nilsson L, Ahlbom A, Farahmand BY, Tomson T: Mortality in a population-based cohort of epilepsy surgery patients. Epilepsia 44: 575-581, 2003

20) Pan HC, Sheehan J, Stroila M, Steiner M, Steiner L: Late cyst formation following gamma knife surgery of arteriovenous malformations. J Neurosurg 102 Suppl: 124-127, 2005

21) Pollock BE, Brown RD Jr: Management of cysts arising after radiosurgery to treat intracranial arteriovenous malformations. Neurosurgery 49: 259265, 2001

22) Quigg M, Barbaro NM: Stereotactic radiosurgery for treatment of epilepsy. Arch Neurol 65: 177-183, 2008

23) Ramos E, Benbadis S, Vale FL: Failure of temporal lobe resection for epilepsy in patients with mesial temporal sclerosis: results and treatment options. J Neurosurg 110: 1127-1134, 2009

24) Régis J, Rey M, Bartolomei F, Vladyka V, Liscak R, Schröttner O, Pendl G: Gamma knife surgery in mesial temporal lobe epilepsy: a prospective multicenter study. Epilepsia 45: 504-515, 2004

25) Rheims S, Fischer C, Ryvlin P, Isnard J, Guenot M, Tamura M, Régis J, Mauguiere F: Long-term outcome of gamma-knife surgery in temporal lobe epilepsy. Epilepsy Res 80: 23-29, 2008
26) Salanova V, Markand O, Worth R: Temporal lobe epilepsy surgery: outcome, complications, and late mortality rate in 215 patients. Epilepsia 43: 170-174, 2002

27) Schramm J: Temporal lobe epilepsy surgery and the quest for optimal extent of resection: a review. Epilepsia 49: 1296-1307, 2008

28) Sindou M, Guenot M, Isnard J, Ryvlin P, Fischer C, Mauguière F: Temporo-mesial epilepsy surgery: outcome and complications in 100 consecutive adult patients. Acta Neurochir (Wien) 148: 39-45, 2006

29) Sperling MR, Harris A, Nei M, Liporace JD, O’Connor MJ: Mortality after epilepsy surgery. Epilepsia 46 Suppl 11: 49-53, 2005

30) Srikijvilaikul T, Najm I, Foldvary-Schaefer N, Lineweaver T, Suh JH, Bingaman WE: Failure of gamma knife radiosurgery for mesial temporal lobe epilepsy: report of five cases. Neurosurgery 54: 1395-1404, 2004

31) Stavem K, Guldvog B: Long-term survival after epilepsy surgery compared with matched epilepsy controls and the general population. Epilepsy Res 63: 67-75, 2005

32) Tanriverdi T, Ajlan A, Poulin N, Olivier A: Morbidity in epilepsy surgery: an experience based on 2449 epilepsy surgery procedures from a single institution. J Neurosurg 110: 1111-1123, 2009

33) Tanriverdi T, Olivier A, Poulin N, Andermann F, Dubeau F: Long-term seizure outcome after mesial temporal lobe epilepsy surgery: corticalamygdalohippocampectomy versus selective amygdalohippocampectomy. J Neurosurg 108: 517-524, 2008

34) Téllez-Zenteno JF, Dhar R, Wiebe S: Long-term seizure outcomes following epilepsy surgery: a systematic review and meta-analysis. Brain 128: 11881198, 2005

35) Tomson T, Nashef L, Ryvlin P: Sudden unexpected death in epilepsy: current knowledge and future directions. Lancet Neurol 7: 1021-1031, 2008

36) Vojtěch Z, Vladyka V, Kalina M, Nešpor E, Seltenreichová K, Šemnická J, Liščák R: The use of radiosurgery for the treatment of mesial temporal lobe epilepsy and long-term results. Epilepsia 50: 2061-2071, 2009

37) Wiebe S, Blume WT, Girvin JP, Eliasziw M: A randomized, controlled trial of surgery for temporal-lobe epilepsy. N Engl J Med 345: 311-318, 2001

38) Yamamoto M, Jimbo M, Hara M, Saito I, Mori K: Gamma knife radiosurgery for arteriovenous malformations: long-term follow-up results focusing on complications occurring more than 5 years after irradiation. Neurosurgery 38: 906-914, 1996

Address reprint requests to: Tetsuro Kawamura, MD, $\mathrm{PhD}$, Department of Neurosurgery, Asanogawa General Hospital, 83 Kosakamachi-Naka, Kanazawa 9208621, Japan.

e-mail: te03@asanogawa-gh.or.jp 